\title{
BMJ Global Health Biopsychosocial factors associated with chronic low back pain disability in rural Nigeria: a population-based cross- sectional study
}

\author{
Chinonso Nwamaka Igwesi-Chidobe, ${ }^{1}$ Bolaji Coker, ${ }^{2}$ Chika N Onwasigwe, ${ }^{3}$ \\ Isaac O Sorinola, ${ }^{4}$ Emma L Godfrey ${ }^{4}$
}

To cite: Igwesi-Chidobe $\mathrm{CN}$, Coker B, Onwasigwe CN, et al. Biopsychosocial factors associated with chronic low back pain disability in rural Nigeria: a populationbased cross-sectional study. BMJ Glob Health 2017;2:e000284. doi:10.1136/ bmjgh-2017-000284

- Additional material is published online only. To view, please visit the journal online (http://dx.doi.org/10.1136/ bmjgh-2017-000284).

Received 6 January 2017 Revised 23 June 2017 Accepted 28 June 2017

\section{CrossMark}

For numbered affiliations see end of article.

\section{Correspondence to}

Dr Chinonso Nwamaka IgwesiChidobe;

chinonso.chidobe@unn.edu.ng and Dr Emma L Godfrey; emma.l.godfrey@kcl.ac.uk

\section{ABSTRACT}

Introduction Many people in Nigeria are living with disability due to chronic low back pain (CLBP), with the greatest burden accounted for by people living in rural Nigeria. However, factors associated with disability in rural Nigeria have not yet been established. We investigated the biomechanical and psychosocial predictors of CLBP disability in a rural Nigerian population.

Methods A cross-sectional study of adults with nonspecific CLBP recruited from rural communities in Enugu State, South-eastern Nigeria. Measures of self-reported and performance-based disability, pain intensity, anxiety and depression, coping strategies, social support, occupational biomechanical factors, illness perceptions and fear avoidance beliefs were collected by trained community health workers. We used univariate and multivariate analyses.

Results 200 individuals were recruited. Psychosocial factors were the most important factors associated with CLBP disability, and accounted for $62.5 \%$ and $49.1 \%$ of the variance in self-reported and performance-based disability, respectively. The significant predictors of self-reported disability were: illness perceptions $(\beta=0.289 ; p<0.0005)$, pain intensity $(\beta=0.230 ; p<0.0005)$, catastrophising ( $\beta=0.210 ; p=0.001)$, fear avoidance beliefs $(\beta=0.198$; $p=0.001)$ and anxiety $(\beta=0.154 ; p=0.023)$. The significant predictors of performance-based disability were: illness perceptions $(\beta=0.366 ; p<0.0005)$, social support $(\beta=0.290 ; p<0.0005)$, fear avoidance beliefs $(\beta=0.189$; $p<0.01)$ and female gender $(\beta=0.184 ; p<0.01)$. Illness concern was the most salient dimension of illness perceptions predicting self-reported and performancebased disability.

Conclusions These results provide evidence which can be used to inform the development of interventions to reduce CLBP disability in rural Nigeria, and may have relevance in other rural African contexts.

\section{INTRODUCTION}

Low back pain (LBP) is the leading cause of years lived with disability in high-income and low-income countries. ${ }^{1-4}$ Its impact is multifactorial including pain, disability

\section{Key questions}

What is already known about this topic?

- Biopsychosocial factors are associated with chronic low back pain disability in high-income countries but the importance of these factors have not been established in rural Nigeria.

- Previous studies in Nigeria have been limited by exclusively focusing on biomechanical outcomes, the use of non-validated measures, not distinguishing between acute and chronic low back pain, or specific and non-specific low back pain, and not measuring pain intensity, sickness absence or functional disability. A few studies that purported to be about chronic low back pain did not use its valid definition.

\section{What are the new findings?}

- This is the first carefully conducted cross-sectional study demonstrating the biopsychosocial factors associated with chronic low back pain disability in any rural African context.

- The results suggest that psychosocial factors may be more important than biomechanical factors in explaining chronic low back pain disability in rural Nigeria. This is at odds with its current management in this context, which focus on a biomedical model.

\section{Recommendations for policy}

- Evidence-based management of chronic low back pain in rural Nigeria should incorporate the biopsychosocial model. This should be reflected in clinical training in Nigeria.

and significant economic costs. It is one of the most expensive conditions in high-income countries costing US $\$ 90.7$ billion, $£ 11$ billion and A $\$ 9.17$ billion in the USA, UK and Australia, respectively, between 1998 and 2001. ${ }^{3}$ The impact is potentially even more devastating in low-income countries. ${ }^{5}$ This is especially true in rural African 
contexts where beliefs, culture and common activities such as fetching water,

farming and carrying heavy objects, combined with high levels of poverty and lack of health services may increase the consequences of living with $\mathrm{LBP}^{67}$

Nigeria appears to have one of the greatest burdens of LBP in the world, possibly accounted for by people living in rural Nigeria. The 1-year prevalence rate of $40 \%-85 \%$ in Nigeria is $>14 \%-51 \%$ reported in other African countries. ${ }^{8-10}$ Furthermore, the point prevalence rate of $33 \%-40 \%$ in Nigeria is $>10 \%-33 \%$ in high-income countries including the UK, Canada and Belgium. ${ }^{311}$ In Nigeria, the burden of LBP is disproportionately greater in rural Nigeria, which has a 1-year prevalence rate ranging between $70 \%$ and $85 \% .^{9} 101213$ This is much higher than the $39 \%$ rate found in urban Nigeria. ${ }^{9}$

Non-specific chronic low back pain (CLBP) is pain or functional discomfort between the 12th rib and the gluteal cleft, with or without radiation to the legs,${ }^{14}$ lasting $>12$ weeks without a specific underlying pathology. ${ }^{15}$ CLBP is responsible for most of the cost and disability associated with LBP in high-income countries. ${ }^{5}$ One year after first onset of LBP, $65 \%-71 \%$ of patients still have pain, ${ }^{16}$ making it predominantly regarded as a chronic condition. ${ }^{5}$ CLBP is likely to increase exponentially in low-income countries as people grow older in environments with limited health resources, infrastructure and research funding. ${ }^{47}$ This is reinforced by factors including maladaptive illness beliefs and health practices, as well as adverse living and working conditions. ${ }^{78-23}$ Furthermore, the majority of people affected by CLBP are in their most productive years of life, which may further exacerbate poverty and inequality in low-income countries. ${ }^{4}$ Studies in Nigeria suggest that biomechanical factors are important in the aetiology of LBP but these studies did not account for the possible influence of psychosocial factors, and did not use the valid definitions of the impact of LBP such as functional disability or work-related disability/sickness absence. ${ }^{124-27}$

The biopsychosocial model of CLBP acknowledges that cognitive, emotional, psychological, behavioural, physical and social factors interact to perpetuate pain, ${ }^{28} 29$ and should be addressed in integrated multimodal interventions. ${ }^{30}{ }^{31}$ In high-income countries, treatments have targeted the biopsychosocial factors associated with pain persistence and CLBP disability in those contexts. For instance, psychological distress, ${ }^{32-35}$ fear avoidance beliefs, ${ }^{28} 34$ 36-39 catastrophising $^{32}{ }^{40-42}$ and illness perceptions ${ }^{43-45}$ have been associated with functional disability in such countries. Occupational biomechanical factors, including heavy lifting and prolonged trunk flexion, have been found to predict work-related outcomes such as duration of sick leave, earnings-related compensation, leaving jobs and inability to carry out normal duties, but not functional disability. ${ }^{46-48}$

The factors associated with CLBP disability in rural Nigeria are unknown, which may help explain the lack of effective treatment of CLBP in this context. ${ }^{40}{ }^{50} \mathrm{We}$ conducted a qualitative study exploring the experiences of people living with chronic LBP in rural Nigeria. This revealed biopsychosocial factors such as illness beliefs, fear avoidance beliefs, catastrophising, anxiety, depression, maladaptive coping, social support and occupational biomechanical factors as important issues in rural Nigeria. ${ }^{50}$ We therefore aimed to investigate the association between these biopsychosocial factors and self-reported and performance-based disability in people living with CLBP in a rural Nigerian population to inform the development of effective interventions in this context. This paper acknowledges the items in the guidelines for Strengthening the Reporting of Observational studies in Epidemiology statement. ${ }^{51}$

\section{METHODS}

\section{Study design and participants}

We conducted a population-based exploratory cross-sectional study in Enugu State, one of the five states of Southeastern Nigeria. Enugu State has a population of over 3 million people according to the 2006 Nigerian census. ${ }^{52}$ The state is made up of 17 local government areas (LGAs), with only 3 of these exclusively urban LGAs. ${ }^{53}$ About $60 \%$ of the population lives in rural areas. ${ }^{53}$ The rural communities are predominantly agrarian with most rural dwellers practising peasant or subsistence farming. ${ }^{53}$ This study was designed to be representative of the rural populations in Enugu State.

\section{Procedures}

Multistage cluster sampling was used to select rural communities, representative of rural populations in Enugu State. Stratified sampling aimed at ensuring equal representation of gender. The 17 LGAs in Enugu State were split into urban and rural LGAs. Enugu South, Enugu North and Enugu East are exclusively urban LGAs and were excluded from the sampling frame. Of the remaining 14 LGAs, 10 LGAs were randomly sampled with computer-generated random numbers. Ten community health workers (CHWs) were recruited from the University of Nigeria Teaching Hospital and trained (for 2 weeks) to collect data. Each CHW was conveniently (familiarity with area) assigned to one of the selected 10 LGAs. They collected the area maps (which contained all the communities in each LGA) of the assigned LGAs from the secretariats supervised by the first author. The lists of the rural communities of the rural LGAs were compiled by the first author. Each CHW randomly selected one community by simple balloting, supervised by the first author. This resulted to a total of 10 rural communities from the 10 LGAs (figure 1).

The traditional heads of the communities facilitated village-wide announcements about the study and emphasised voluntary participation. Announcements informed people with CLBP, who were interested in the study, to meet on a particular day at selected community centressuch as primary healthcare centres or schools in each 
LGAs

Aninri

Communities/villages

Nkanu East Oduma Ameke

Igboeze North Oji river

Nsukka

Igbo etiti

Isiuzo

Udenu

Uzo uwani

Nkanu West
Amagunze

Umuagama

Agbada Inyi

Edem Ani

Amagu-Uwenu

Mgbuji Eha-Amufu Iheakpu Obollo Afor

Adaba Nkume

Ukwa

Figure 1 Selected communities and corresponding local government areas (LGAs).

community. The CHWs provided information sheets to the potential participants, and gave them oral explanations about the study. Potential participants that indicated interest in the study were then given another appointment at the community centre. On the second appointment, the CHWs used body charts to identify areas of pain. They screened participants using questions based on a simple checklist to rule out any 'red flags' for back pain by excluding LBP associated with underlying serious pathology, radiculopathy or spinal stenosis. ${ }^{54} 55$ This is congruent with evidence-based guidelines for diagnosing LBP $^{55-58}$ The CHWs then obtained informed consent via signature or thumb print. The eligible participants were stratified into males and females, and were then randomly selected by balloting. Each CHW collected data from 20 participants from each LGA, making up a total of 200 participants in this study.

\section{Variables and measurement}

All measures were cross-culturally adapted into Igbo (the native language in Enugu) using evidence-based guidelines, ${ }^{59}$ and psychometrically tested to ensure they retained the validity and reliability of the original measures. Due to low literacy rates $(50 \%)$, measures were interviewer-administered except for the Back Performance Scale (BPS), a 5-item back-specific performance-based measure of trunk mobility-related activities ${ }^{60}$ which was objectively assessed by the CHWs. The CHWs read out each questionnaire item, and concurrently presented the corresponding Likert scale or questionnaire options to participants as 'flash cards'. Participants were then asked to verbally select an option which was recorded on the questionnaires by the CHWs. Interview administration was randomly checked by the first author for each CHW.

Self-reported disability was assessed with the 24-item (yes or no) Roland Morris Disability Questionnaire (RMDQ), a back pain-specific measure ${ }^{61}$ and the 36 -item WHO Disability Assessment Schedule (WHODAS V.2.0), a generic measure of disability, made back specific by

replacing 'health condition' with 'back pain', in line with the recommendations of the developers. ${ }^{62}{ }^{63}$ WHODAS V.2.0 emphasises six domains of disability: cognition, mobility, self-care, getting along with people, life activities and participation, and is measured on a 5-point Likert scale ranging from 0 to 5 ('none' to 'extreme/ cannot do'). Higher RMDQ and WHODAS scores signify greater disability levels. RMDQ and WHODAS V.2.0 conceptualise disability at three levels: body structures and function, activities and participation and environmental factors.

Pain intensity was assessed with the 11-point numerical box scale (BS-11) ${ }^{6465}$ Six anchors of Igbo pain descriptors included an additional four anchors for response 2, 4,6 and 8 to improve clarity in this population with low literacy $^{65-67}$ : $0=$ no pain, $2=$ small or mild pain, $4=$ pain that is not too much or moderate pain, $6=$ severe pain, $8=$ verysevere pain, $10=$ worst pain imaginable. The first four anchors correspond to the more commonly used 'no pain', 'mild', 'moderate' and 'severe pain' descriptors. Additional extreme anchors of pain descriptors helped to minimise ceiling effects. ${ }^{68}$

Anxiety and depression were measured by the 14-item Hospital Anxiety and Depression Scale (HADS). ${ }^{69}$ There are seven items in each subscale with each item having scores ranging from 0 to 3 . Summing the scores of anxiety and depression reflects a score of emotional distress. Higher scores denote greater emotional distress.

Coping strategies were measured with the 42-item Coping Strategies Questionnaire. ${ }^{70}$ It consists of seven subscales (diverting attention, reinterpreting pain sensation, catastrophising, ignoring sensations, praying or hoping, coping self-statements and increased behavioural activities). Each subscale has six items with a minimum score of 0 and a maximum score of 36 , with higher scores indicating greater use of a particular coping strategy. An additional two items assess overall effectiveness of pain control and ability to decrease pain.

Social support was measured using the 12-item Multidimensional Scale of Perceived Social Support (MSPSS). ${ }^{71}$ MSPSS has 12 items which can be summed as one total score, or as three subscales (family, friends or significant other) of four items each, depending on the source of social support. Each item has a 7-point Likert scale with values ranging from 1 (strongly disagree) to 7 (strongly agree). A greater score indicates more perceived social support.

Illness perceptions was assessed using the 9-item Brief Illness Perception Questionnaire (BIPQ) ${ }^{72}$ Each item, measured on a Likert scale ranging from 0 to 10 , assesses one dimension of illness perceptions. Eight items (consequences, timeline, personal control, treatment control, identity, illness concern, coherence and emotional representation) may be combined as one total score, or each item may be assessed separately to give eight dimensions of illness perceptions. The ninth item is the causal item which is open, and can be analysed by 
grouping participants' responses into relevant categories depending on the research question.

Fear avoidance beliefs was measured with the 16-item Fear Avoidance Beliefs Questionnaire (FABQ) ${ }^{73}$ FABQ assesses the extent to which pain is believed to be caused or aggravated by general physical activity (FABQ-PA) and work-related activities (FABQ-W). These represent the two subscales of the measure. FABQ-PA has five items, each scored with a Likert scale ranging from 0 (completely disagree) to 6 (completely agree). One item is a distractor and is not scored. FABQ-W has 11 items, each having a Likert scale ranging from 0 (completely disagree) to 6 (completely agree), but four items are distractors, and do not contribute to total score. The two subscales can be summed to give a total score with higher scores reflecting stronger fear avoidance beliefs.

Biomechanical factors were assessed with the Occupational Risk Factor Questionnaire (ORFQ) with total scoring of the items measuring biomechanical factors such as bending, twisting, lifting, pulling, pushing, forceful movements and static postures like prolonged sitting, awkward postures and whole body vibrations. ${ }^{74}$ Higher scores reflect greater exposure to biomechanical factors.

\section{Fidelity checks/bias control}

Only CHWs that passed post-training examinations were involved in data collection. The first author visited each CHW during data collection without prior arrangement, and assessed their interviewing styles, data recording and assessment. Furthermore, a participant from each CHW was randomly selected, and the performance-based disability was re-assessed by the first author.

\section{Statistical analyses}

Data were analysed using IBM SPSS V.22 and were two-tailed. Data were assessed for normality using visual (normal distribution curve and Q-Q plot), and statistical methods (Kolmogorov-Smirnov, Shapiro-Wilk's test and Skewness/Kurtosis scores). Percentages and means with $\mathrm{SD}$ were used to summarise demographic variables. Means with SD, and medians with IQRs were used to summarise all disability and biopsychosocial variables. Univariate analyses were done with t-test, analysis of variance and correlation analyses to determine the association of demographic variables with disability. The significant demographic factors $(\mathrm{p}<0.05)$ were included in sequential multiple regression analyses to control their effects. Pearson's and Spearman's correlation coefficients were used to investigate the bivariate relationship between each disability measure, and the other variables (biopsychosocial factors), according to the normality of data. Variables with significant correlations with RMDQ and BPS were entered into sequential multiple regression analyses. Correlation coefficients (r) above 0.1 with $\mathrm{p}<0.05$ was the a priori set level for inclusion in the regression models. The assessment of the assumptions about collinearity and residuals was done by entering predictor variables that had significant correlations with RMDQ and BPS into two standard multiple regression analyses.

Sequential multiple regression analyses were used to account for the effects of sociodemographic factors, calculate standardised beta coefficients and estimate the unique variance of self-reported (RMDQ) and performance-based (BPS) disability explained by each significant predictor. WHODAS V.2.0 (self-reported generic disability) was not included in the regression analyses, but was used to describe the characteristics of the population surveyed in order to compare disability levels with population norms and to identify disability domains affected. ${ }^{62}$ Interaction analyses were used to determine if relationships between disability variables (RMDQ and BPS) and their predictor variables were influenced by other predictor variables. Bonferroni corrections were applied to minimise the risk of type 1 error. Post hoc diagnostic tests (graphical and statistical analyses of residuals) were used to determine the accuracy of the regression models that predicted self-reported and performance-based disability.

\section{RESULTS}

Figure 2 shows the process for selection of the participants in this study. It was difficult recruiting men; therefore, additional men were recruited from work sites in each of the 10 communities. Three of these men could not be contacted further, and one man who started the survey, left before completing it. This gave a completion rate of $98 \%$. A total of 88 men and 112 women were surveyed. Rigorous training of CHWs and interviewer-administration of measures ensured there were no missing data.

Fidelity to data collection protocols was confirmed. CHWs maintained neutrality during the interviews, discouraged digression and distraction and did not change the wording and sequence of questions in the battery of measures. The assessment of performance-based disability was adequate. For instance, CHWs used the tape measures adequately to assess $10 \mathrm{~cm}$ between the feet, and measured the distance between the fingertips and the floor, for the finger-tip-to-floor test. The performance-based disability levels recorded by the first author and the CHWs were similar for the randomly selected participants (exact values or differences of not more than 2 were observed).

Table 1 shows the demographic characteristics of the participants. Table 2 shows the summary scores of the biopsychosocial variables. Self-reported generic disability score of 22.81 measured with the WHODAS V.2.0 corresponds to the 85 th percentile of population norms. ${ }^{62}$ The domains of disability with the highest scores were participation, mobility and life activities.

Table 3 shows the bivariate Pearson's and Spearman's correlation coefficients between each disability measure (RMDQ, WHODAS V.2.0 and BPS), and the biopsychosocial variables. A strong significant positive correlation 


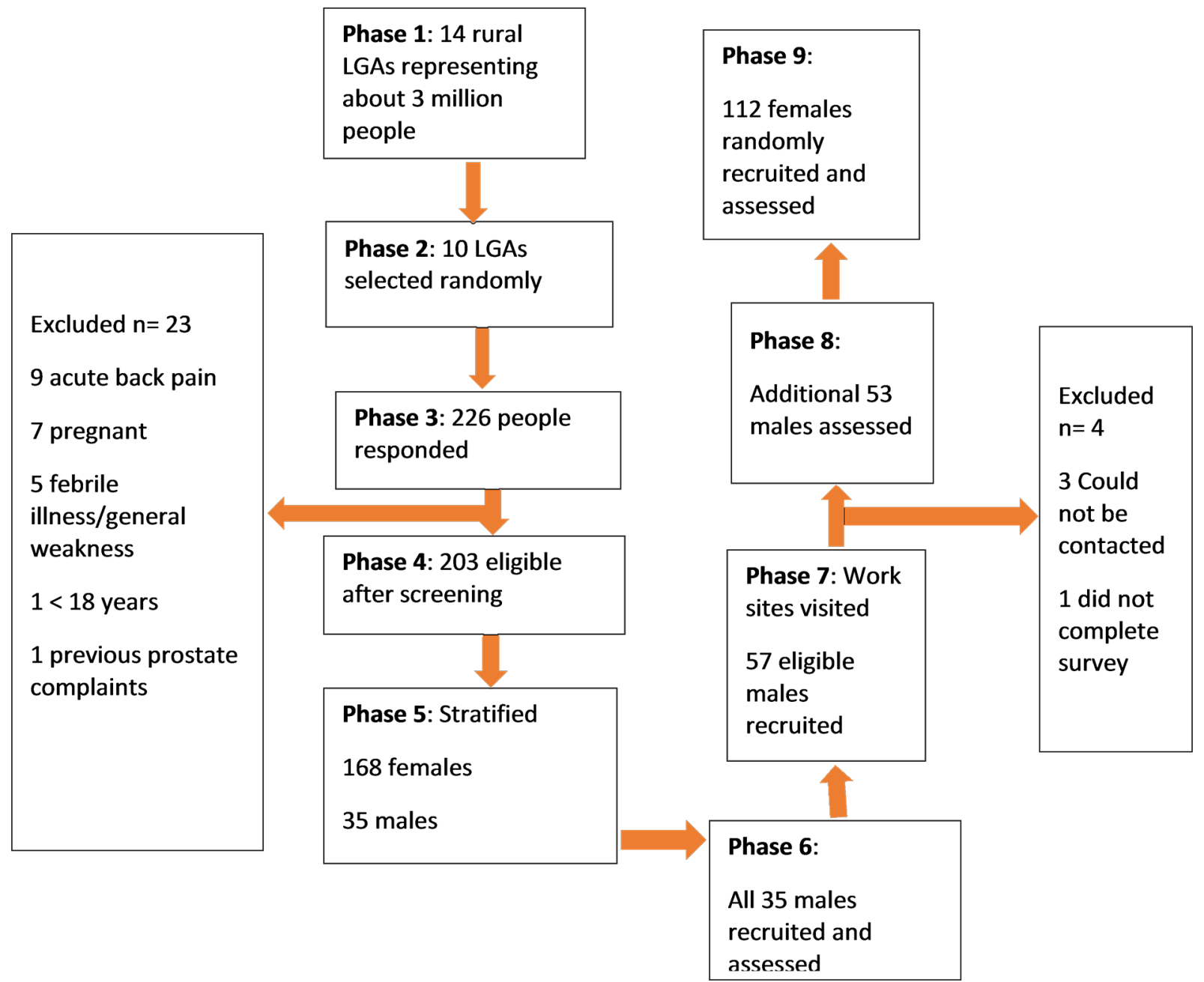

Figure 2 Summary of sampling and response rates. LGA, local government area.

between back-specific self-reported disability (RMDQ) and back-specific performance-based disability (BPS) $(\mathrm{r}=0.646, \mathrm{n}=200, \mathrm{p}<0.001)$ was found. A moderate significant correlation between generic self-reported disability (WHODAS) and back-specific self-reported disability $\left(r_{s}=0.537, \quad n=200, \quad p<0.001\right)$ was found. Correlation between generic self-reported disability and back-specific performance-based disability was comparatively weaker but still significant $\left(r_{\mathrm{s}}=0.343, \mathrm{n}=200, \mathrm{p}<0.001\right)$. Predictor biopsychosocial variables entered into the regression models for RMDQ and BPS, based on the a priori set correlation coefficients were pain intensity, anxiety and depression, social support, biomechanical factors, illness perceptions, fear avoidance beliefs and coping strategies. Of the subscales of the coping strategies questionnaire, only catastrophising was included in multiple regression analyses to avoid multicollinearity. Catastrophising has been implicated in the experience of CLBP in this population in a previous study. ${ }^{50}$

Table 4 shows the univariate analyses done to explore the influence of demographic variables, in order to identify and account for their influence in multiple regression analyses. Being 'widowed' and 'unemployed for health reasons' reached statistical significance and were included in the multiple regression analysis with self-reported disability (RMDQ) as the criterion variable. Marital and work status were excluded from the multiple regression analysis with performance-based disability (BPS) as the criterion variable as none of the categories was significantly associated with BPS.

Table 5 shows the sequential multiple regression analysis predicting self-reported disability. In model 1 , all demographic variables significantly associated with RMDQ (table 4) were entered into the first block of a sequential multiple regression to control their effects. This model explained $18.1 \%$ of the variance in $R M D Q$ (adjusted $R^{2}=0.181$ ), and was significant ( $F$ $(5,194)=9.824, \mathrm{p}<0.0001)$. Model 2 , in which other significant correlates (table 3) were added, explained significantly more variance $\left(R^{2}\right.$ change $=0.45, F \quad(7$, $187)=33.75, \mathrm{p}<0.0001)$ with the model explaining $62.5 \%$ of the variance in self-reported disability (adjusted $\left.\mathrm{R}^{2}=0.625\right)$. The significant predictors of $\mathrm{RMDQ}$ were illness perceptions $(\beta=0.289 ; \mathrm{p}<0.0001)$, pain intensity $(\beta=0.230 ; p<0.0001)$, catastrophising $(\beta=0.210 ; p=0.001)$, fear avoidance beliefs $(\beta=0.198 ; \mathrm{p}=0.001)$ and anxiety 


\begin{tabular}{|c|c|c|}
\hline $\mathrm{n}=\mathbf{2 0 0}$ & n (\%) & Mean (SD) \\
\hline \multicolumn{3}{|l|}{ Gender } \\
\hline Female & $112(56.0)$ & \\
\hline Male & $88(44.0)$ & \\
\hline Age (years) & & $48.6(12.0)$ \\
\hline Education (years) & & $7.0(6.4)$ \\
\hline \multicolumn{3}{|l|}{ Current marital status } \\
\hline Currently married & $143(71.5)$ & \\
\hline Widowed & $31(15.5)$ & \\
\hline Never married & $22(11.0)$ & \\
\hline Cohabiting & $2(1.0)$ & \\
\hline Separated & $2(1.0)$ & \\
\hline \multicolumn{3}{|l|}{ Work status } \\
\hline $\begin{array}{l}\text { Self-employed (own business or } \\
\text { farming) }\end{array}$ & $125(62.5)$ & \\
\hline Paid work & $31(15.5)$ & \\
\hline $\begin{array}{l}\text { Non-paid work (volunteer or } \\
\text { charity) }\end{array}$ & $16(8.0)$ & \\
\hline Keeping house/homemaker & $13(6.5)$ & \\
\hline Student & $7(3.5)$ & \\
\hline Unemployed (health reasons) & $4(2.0)$ & \\
\hline Unemployed (other reasons) & $3(1.5)$ & \\
\hline Retired & $1(0.5)$ & \\
\hline
\end{tabular}

$(\beta=0.154 ; p=0.023)$. Female gender $(\beta=0.103 ; p=0.044)$ and depression $(\beta=-0.107 ; p=0.044)$ barely reached statistical significance. Table 6 shows the sequential multiple regression analysis predicting performance-based disability. In model 1, all demographic variables significantly associated with BPS (table 4) were entered into the first block of a sequential multiple regression to control their effects. This model explained $13.6 \%$ of the variance in BPS and was significant $(F(3,196)=11.418$, $\mathrm{p}<0.0001)$. Model 2, in which other significant correlates (table 3 ) were added, explained significantly more variance $\left(\mathrm{R}^{2}\right.$ change $\left.=0.37, \mathrm{~F}(7,189)=20.507, \mathrm{p}<0.0001\right)$, with the model explaining $49.1 \%$ of the variance in performance-based disability (adjusted $\mathrm{R}^{2}=0.491$ ). The significant predictors of BPS were illness perceptions $(\beta=0.366$; $\mathrm{p}<0.0001)$, social support $(\beta=0.290 ; \mathrm{p}<0.0001)$, fear avoidance beliefs $(\beta=0.189 ; \mathrm{p}=0.005)$ and female gender $(\beta=0.184 ; p=0.001)$.

As BIPQ was the strongest predictor of both self-reported and performance-based disability, it was further analysed to understand the contribution of each item of the BIPQ (eight dimensions of illness perceptions).

In tables 7 and 8 , each of the eight items of the BIPQ were entered as predictors into the sequential multiple regression analysis that predicted RMDQ (table 5) and BPS (table 6) for model 2, in place of total BIPQ score. The total BIPQ score is copied from tables 5 and 6 for
Table 2 Summary scores of the biopsychosocial variables

\begin{tabular}{|c|c|c|}
\hline Variable, $n=200$ & Mean (SD) & Median (IQR) \\
\hline $\mathrm{RMDQ}$ & $11.1(6.5)$ & $10.5(6.0,17.0)$ \\
\hline BPS & $6.6(3.7)$ & $6.5(4.0,9.8)$ \\
\hline WHODAS (total) & $22.8(15.7)$ & $21.4(9.9,33.7)$ \\
\hline Participation & $30.9(21.4)$ & $28.1(15.6,46.9)$ \\
\hline Mobility & $30.8(22.5)$ & $30.0(10.0,45.0)$ \\
\hline Life activities & $30.3(22.4)$ & $25.0(12.5,46.9)$ \\
\hline Cognition & $17.4(19.7)$ & $12.5(0.0,29.2)$ \\
\hline Getting along & $15.6(17.9)$ & $10.0(0.0,25.0)$ \\
\hline Self-care & $11.8(14.6)$ & $6.3(0.0,18.8)$ \\
\hline BS-11 & $5.3(2.1)$ & $5.0(4.0,7.0)$ \\
\hline \multicolumn{3}{|l|}{ HADS } \\
\hline Anxiety & $7.2(4.5)$ & $7.0(3.0,11.0)$ \\
\hline Depression & $7.5(3.5)$ & $8.0(5.3,10.0)$ \\
\hline \multicolumn{3}{|l|}{ CSQ } \\
\hline Control & $3.9(1.3)$ & $4.0(3.0,5.0)$ \\
\hline Decrease pain & $3.6(1.3)$ & $3.5(3.0,4.0)$ \\
\hline Praying/hoping & $27.8(7.3)$ & $30.0(25.0,33.0)$ \\
\hline Coping self-statements & $23.8(7.0)$ & $25.0(19.0,29.0)$ \\
\hline Diverting attention & $17.9(9.3)$ & $20.0(11.0,25.0)$ \\
\hline $\begin{array}{l}\text { Increased behavioural } \\
\text { activities }\end{array}$ & $16.9(8.1)$ & $19.0(10.0,23.8)$ \\
\hline Ignoring sensations & $16.6(7.5)$ & $18.0(10.0,22.0)$ \\
\hline $\begin{array}{l}\text { Reinterpreting pain } \\
\text { sensation }\end{array}$ & $15.1(8.9)$ & $17.0(7.0,22.0)$ \\
\hline Catastrosphising & $13.6(8.2)$ & $13.0(7.0,20.0)$ \\
\hline MSPSS & $62.4(13.3)$ & $64.0(52.0,72.0)$ \\
\hline ORFQ & $4.6(4.7)$ & $3.0(2.0,6.0)$ \\
\hline $\mathrm{BIPQ}$ & $37.5(8.7)$ & $38.0(32.0,44.0)$ \\
\hline FABQ & 39.2 (15.9) & $43.0(23.3,53.0)$ \\
\hline
\end{tabular}

BIPQ, Brief Illness Perception Questionnaire; BPS, Back Performance Scale; BS-11, 11-point box scale; CSQ, Coping Strategies Questionnaire; FABQ, Fear Avoidance Beliefs Questionnaire; HADS, Hospital Anxiety and Depression Scale; MSPSS, Multidimensional Scale of Perceived Social Support; RMDQ, Roland Morris Disability Questionnaire; WHODAS, WHO Disability Assessment Schedule.

comparison with the BIPQ items while the other variables from tables 5 and 6 are not shown in tables 7 and 8 for brevity. A Bonferroni-adjusted significance level of 0.0063 (eight analyses with each analysis including one BIPQ item) was used to account for the increased possibility of type I error. In table 7 , illness concern $(\beta=0.316 ; p<0.0001)$, emotional representation $(\beta=0.299$; $\mathrm{p}<0.0001)$, consequences $(\beta=0.287 ; \mathrm{p}<0.0001)$, identity $(\beta=0.202 ; p=0.001)$ and timeline $(\beta=0.157 ; p=0.002)$ were significant. Illness concern produced the strongest model (adjusted $\mathrm{R}^{2}=0.631$ ), compared with the other $\mathrm{BIPQ}$ items, and explained more variance in RMDQ than the model with total BIPQ (adjusted $\mathrm{R}^{2}=0.625$ ). Other BIPQ 


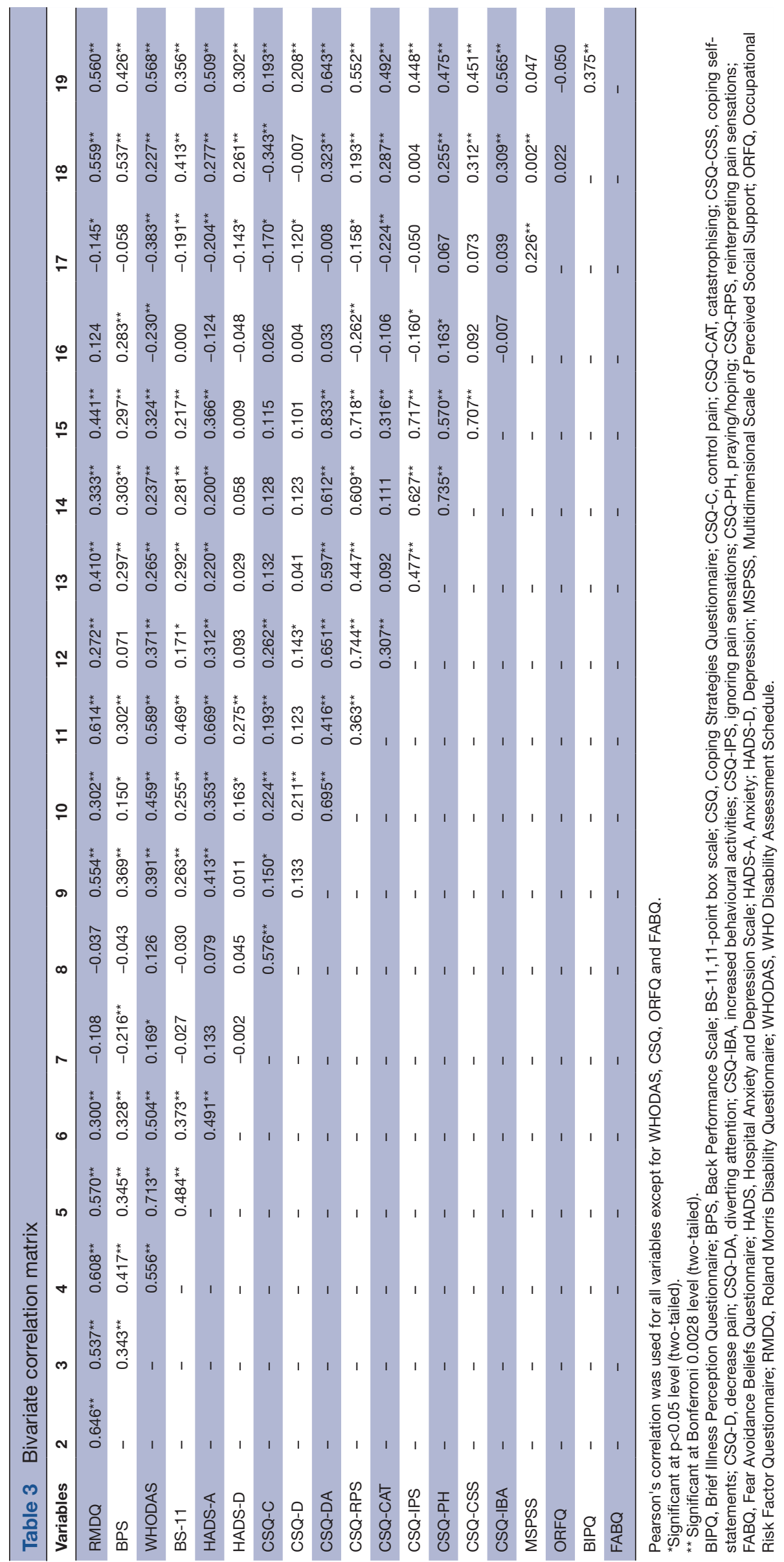


Table 4 Influence of demographic variables on self-reported and performance-based disability

\begin{tabular}{|c|c|c|c|c|}
\hline \multirow[b]{2}{*}{ Variables, $n=200$} & \multicolumn{2}{|l|}{ RMDQ } & \multicolumn{2}{|l|}{ BPS } \\
\hline & $t$ (p value) & B (p value) & $t$ ( $p$ value) & B (p value) \\
\hline \multirow{2}{*}{$\begin{array}{l}\text { Gender } \\
\text { (female) }\end{array}$} & $3.0(0.003)$ & $2.7(0.003)$ & $3.8(<0.0001)$ & $1.9(<0.0001)$ \\
\hline & $r$ (p value) & B ( $p$ value) & $r$ (p value) & $B$ ( $p$ value) \\
\hline $\begin{array}{l}\text { Age } \\
\text { (years) }\end{array}$ & $0.3(<0.0001)$ & $0.1(<0.0001)$ & $0.3(<0.0001)$ & $0.1(<0.0001)$ \\
\hline \multirow[t]{2}{*}{ Education (years) } & $-0.3(<0.0001)$ & $-0.3(<0.0001)$ & $-0.2(0.001)$ & $-0.1(0.001)$ \\
\hline & $F$ ( $p$ value $)$ & B (p value) & $F$ ( $p$ value) & B ( $p$ value) \\
\hline Marital status & $2.7(0.031) d f=4,195$ & $\begin{array}{l}\text { Never married: } 4.5(0.333) \\
\text { Currently married: } 6.8(0.130) \\
\text { Separated: } 7.0(0.267) \\
\text { Widowed: } 10.8(0.019) \\
\text { Cohabiting: reference }\end{array}$ & $4.4(0.002) d f=4,195$ & $\begin{array}{l}\text { Never married: } 1.1(0.665) \\
\text { Currently married: } 1.8(0.479) \\
\text { Separated: } 3.5(0.325) \\
\text { Widowed: } 4.5(0.086) \\
\text { Cohabiting: reference }\end{array}$ \\
\hline Work status & $4.0(<0.0001) d f=7,192$ & $\begin{array}{l}\text { Paid work: }-2.8(0.457) \\
\text { Self-employed: } 1.2(0.731) \\
\text { Non-paid work: } 1.3(0.740) \\
\text { Student: }-2.0(0.632) \\
\text { Homemaker: } 4.1(0.307) \\
\text { Retired: }-10.3(0.149) \\
\text { Unemployed for health } \\
\text { reasons: } 9.7(0.042) \\
\text { Unemployed for other } \\
\text { reasons: reference }\end{array}$ & $2.5(0.018) d f=7,192$ & $\begin{array}{l}\text { Paid work: }-1.4(0.519) \\
\text { Self-employed: } 0.5(0.812) \\
\text { Non-paid work: } 0.1(0.963) \\
\text { Student: }-1.0(0.672) \\
\text { Homemaker: } 3.2(0.163) \\
\text { Retired: }-0.3(0.936) \\
\text { Unemployed for health } \\
\text { reasons: } 1.4(0.605) \\
\text { Unemployed for other } \\
\text { reasons: reference }\end{array}$ \\
\hline
\end{tabular}

Sex, marital status and occupation are categorical variables.

BPS, Back Performance Scale; B, correlation coefficient; F, analysis of variance; RMDQ, Roland Morris Disability Questionnaire; r, correlation; rs/ r, Spearman's/Pearson's correlation; t, test.

items produced weaker models than illness concern and the total BIPQ score. In table 8, the total BIPQ score explained more variance in BPS than any individual item of the BIPQ. Illness concern $(\beta=0.294 ; \mathrm{p}<0.0001)$, timeline $(\beta=0.255 ; p<0.0001)$, consequences $(\beta=0.223$; $\mathrm{p}=0.001)$ and personal control $(\beta=-0.205 ; \mathrm{p}<0.0001)$ were the significant BIPQ items predicting performance-based disability. Notably, illness concern consistently remained the strongest BIPQ item predicting both self-reported and performance-based disability.

The ninth Igbo-BIPQ item is open and is not included in the BIPQ total scoring. Categorical analysis of the ninth BIPQ item was therefore performed as shown in table 9 . Most participants attributed CLBP to biomechanical factors, followed by medical factors (eg, infection). The least attributed factor was spiritual. Having no attributed cause (do not know) was significantly associated with both self-reported and performance-based disability. Spiritual causal understanding was significantly associated with self-reported disability while natural/gender factors (belief that back pain was due to inheritance from participant's family or gender) were significantly associated with performance-based disability.

Interaction terms were added for depression as it had a positive correlation with self-reported disability (table 3 ; $\mathrm{r}=0.300$ ), which had a negative effect in the regression model for RMDQ (table 5; $\beta=-0.200$ ). Therefore, an interaction test was done with HADS-D being combined with each independent significant predictor of RMDQ in table 5. Similarly, an interaction test was done for occupational biomechanical factors which people associated with back pain in a previous qualitative study, ${ }^{50}$ but which had a negative correlation with RMDQ (table 3), and was not a predictor of RMDQ (table 5). ORFQ was combined with each of the significant predictors of RMDQ in table 5. The only significant interactions in relation to RMDQ were between biomechanical factors (ORFQ) and depression (HADS-D) $(\mathrm{p}=0.031)$. Only the significant interaction test is presented in online supplementary table 1 . However, the interaction term was not significant in the regression model that predicted self-reported disability (see online supplementary table 2).

Graphical and statistical analyses of residuals showed that the regression models were accurate. A sample size of 200 at the largest regression effect size found in this study ( $f^{2}=0.366$ ) at $\alpha$ of 0.05 with 12 predictors showed that this study had a $99.9 \%$ power to detect predictors of disability.

\section{DISCUSSION}

This is the first study that investigated the biopsychosocial factors associated with CLBP disability in any rural African context. The most important predictors of CLBP disability in rural Nigeria were illness perceptions and fear avoidance beliefs, since they predicted both self-reported 
Table 5 Sequential multiple regression analysis predicting self-reported disability (RMDQ)

\begin{tabular}{|c|c|c|c|c|c|c|}
\hline \multirow[b]{2}{*}{ Variable, $n=200$} & \multicolumn{3}{|l|}{ Model 1} & \multicolumn{3}{|l|}{ Model 2} \\
\hline & B (95\% Cl) & SEB & $\beta$ (p value) & B $(95 \% \mathrm{Cl})$ & SEB & $\beta$ (p value) \\
\hline $\begin{array}{l}\text { Gender (female) } \\
\text { (male=reference) }\end{array}$ & $\begin{array}{l}1.732 \\
(-0.6 \text { to } 3.5)\end{array}$ & 0.907 & $0.133(0.058)$ & $\begin{array}{l}1.343 \\
(0.04 \text { to } 2.6)\end{array}$ & 0.662 & $0.103(0.044)$ \\
\hline Age & $\begin{array}{l}0.050 \\
(-0.33 \text { to } 0.13)\end{array}$ & 0.042 & $0.093(0.235)$ & $\begin{array}{l}0.015 \\
(-0.04 \text { to } 0.07)\end{array}$ & 0.029 & $0.028(0.610)$ \\
\hline Education & $\begin{array}{l}-0.244 \\
(-0.4 \text { to } 0.09)\end{array}$ & 0.079 & $\begin{array}{l}-0.241 \\
(0.002)\end{array}$ & $\begin{array}{l}-0.039 \\
(-0.15 \text { to } 0.07)\end{array}$ & 0.057 & $-0.039(0.488)$ \\
\hline $\begin{array}{l}\text { Marital status (widowed) } \\
\text { (Other marital status=reference) }\end{array}$ & $\begin{array}{l}2.016 \\
(-0.55 \text { to } 4.58)\end{array}$ & 1.302 & $\begin{array}{l}0.113 \\
(0.123)\end{array}$ & $\begin{array}{l}0.024 \\
(-1.76 \text { to } 1.81)\end{array}$ & 0.903 & $0.001(0.979)$ \\
\hline $\begin{array}{l}\text { Work status (unemployed- } \\
\text { health reasons) } \\
\text { (other work status=reference) }\end{array}$ & $\begin{array}{l}10.448 \\
(4.48 \text { to } 16.42)\end{array}$ & 3.029 & $0.226(0.001)$ & $\begin{array}{l}3.717 \\
(-0.53 \text { to } 7.97)\end{array}$ & 2.154 & $0.080(0.086)$ \\
\hline Pain (BS-11) & & & & $\begin{array}{l}0.718 \\
(0.37 \text { to } 1.07)\end{array}$ & 0.177 & $\begin{array}{l}0.230 \\
(<0.0001)\end{array}$ \\
\hline Anxiety (HADS-A) & & & & $\begin{array}{l}0.224 \\
(0.03 \text { to } 0.42)\end{array}$ & 0.098 & $0.154(0.023)$ \\
\hline Depression (HADS-D) & & & & $\begin{array}{l}-0.200 \\
(-0.40 \text { to } 0.01)\end{array}$ & 0.099 & $-0.107(0.044)$ \\
\hline Catastrophising (CSQ) & & & & $\begin{array}{l}0.167 \\
(0.07 \text { to } 0.26)\end{array}$ & 0.049 & $0.210(0.001)$ \\
\hline Illness perceptions (BIPQ) & & & & $\begin{array}{l}0.215 \\
(0.14 \text { to } 0.29)\end{array}$ & 0.038 & $\begin{array}{l}0.289 \\
(<0.0001)\end{array}$ \\
\hline Fear avoidance beliefs (FABQ) & & & & $\begin{array}{l}0.081 \\
(0.03 \text { to } 0.13)\end{array}$ & 0.024 & $0.198(0.001)$ \\
\hline $\begin{array}{l}\text { Occupational biomechanical } \\
\text { factors (ORFQ) }\end{array}$ & & & & $\begin{array}{l}0.017 \\
(-0.12 \text { to } 0.15)\end{array}$ & 0.068 & $0.013(0.796)$ \\
\hline $\mathrm{R}^{2}$ & 0.202 & & & 0.647 & & \\
\hline$R^{2}$ change & 0.202 & & & 0.445 & & \\
\hline$F$ for change in $R^{2}$ & $F(5,194)=9.82$ & $0.0001)$ & & $F(7,187)=33.74$ & $<0.0001)$ & \\
\hline Adjusted $\mathrm{R}^{2}$ & 0.181 & & & 0.625 & & \\
\hline
\end{tabular}

B, unstandardised beta; $\beta$, standardised beta; BIPQ, Brief Illness Perception Questionnaire; BS-11,11-point box scale; CSQ, Coping Strategies Questionnaire; FABQ, Fear Avoidance Beliefs Questionnaire; HADS, Hospital Anxiety and Depression Scale; HADS-A, Anxiety; HADS-D, Depression; ORFQ, Occupational Risk Factor Questionnaire; RMDQ, Roland Morris Disability Questionnaire; SEB, SE of beta.

and performance-based disability. Pain intensity, catastrophising and anxiety also predicted self-reported disability. Social support and female gender also predicted performance-based disability. Occupational biomechanical factors did not predict CLBP disability in this study in rural Nigeria.

The results of this study support previous evidence in high-income countries suggesting that illness perceptions are one of the key determinants of self-reported CLBP disability; the second strongest factor being pain self-efficacy. ${ }^{45}$ Stronger illness perceptions in this study reflected a more threatening view of back pain. ${ }^{72}$ Whereas illness concern was the most important dimension of illness perceptions predicting both self-reported and performance-based disability in this study; perceived illness timeline, identity and personal control were more important in a UK study. ${ }^{45}$ Another UK-based prospective cohort study found that baseline perceived consequences, timeline, personal and treatment control were associated with CLBP disability in patients receiving treatment in primary care. ${ }^{43}$ Pooled evidence from 36 countries in North America, Central and South America, Europe, Australasia and Asia showed that perceived consequences, identity, timeline and control were the most predictive of clinical outcomes. ${ }^{75}$

Differences in illness perceptions may be due to different population characteristics, as no previous study involved African patients. ${ }^{43} 4575$ As suggested in qualitative studies, ${ }^{49}{ }^{50}$ participants in this population may have less clinical information about back pain; and may have received several specific diagnoses and more promises of cure than their Western counterparts. This may have increased illness concern when a resolution of their symptoms was not achieved. In contrast, Western patients are often given non-specific diagnosis, educated about the chronic nature of CLBP and the 
Table 6 Sequential multiple regression analysis predicting performance-based disability (BPS)

\begin{tabular}{|c|c|c|c|c|c|c|}
\hline \multirow[b]{2}{*}{ Variable, $n=200$} & \multicolumn{2}{|l|}{ Model 1} & \multicolumn{3}{|c|}{ Model 2} & \multirow[b]{2}{*}{$\beta$ (p value) } \\
\hline & B $(95 \% \mathrm{Cl})$ & SEB & $\beta$ (p value) & B $(95 \% \mathrm{Cl})$ & SEB & \\
\hline $\begin{array}{l}\text { Gender (female) } \\
\text { (male=reference) }\end{array}$ & $\begin{array}{l}1.829 \\
\text { (0.85 to } 2.81)\end{array}$ & 0.495 & $0.248(<0.0001)$ & $\begin{array}{l}1.358 \\
\text { (0.58 to } 2.14)\end{array}$ & 0.395 & $0.184(0.001)$ \\
\hline Age & $\begin{array}{l}0.076 \\
\text { (0.03 to } 0.12)\end{array}$ & 0.024 & $0.250(0.001)$ & $\begin{array}{l}0.033 \\
(-0.004 \text { to } 0.07)\end{array}$ & 0.019 & $0.108(0.082)$ \\
\hline Education & $\begin{array}{l}-0.033 \\
(-0.12 \text { to } 0.06)\end{array}$ & 0.045 & $-0.058(0.464)$ & $\begin{array}{l}-0.018 \\
(-0.09 \text { to } 0.06)\end{array}$ & 0.037 & $-0.031(0.628)$ \\
\hline Pain (BS-11) & & & & $\begin{array}{l}0.155 \\
(-0.07 \text { to } 0.38)\end{array}$ & 0.115 & $0.088(0.182)$ \\
\hline Anxiety (HADS) & & & & $\begin{array}{l}0.051 \\
(-0.08 \text { to } 0.18)\end{array}$ & 0.064 & $0.062(0.424)$ \\
\hline Depression (HADS) & & & & $\begin{array}{l}0.091 \\
(-0.04 \text { to } 0.22)\end{array}$ & 0.064 & $0.086(0.160)$ \\
\hline Catastrophising (CSQ) & & & & $\begin{array}{l}-0.018 \\
(-0.08 \text { to } 0.05)\end{array}$ & 0.032 & $-0.040(0.580)$ \\
\hline Social support (MSPSS) & & & & $\begin{array}{l}0.08 \\
(0.05 \text { to } 0.11)\end{array}$ & 0.014 & $0.290(<0.0001)$ \\
\hline Illness perceptions (BIPQ) & & & & $\begin{array}{l}0.154 \\
\text { (0.11 to } 0.20)\end{array}$ & 0.024 & $0.366(<0.0001)$ \\
\hline $\begin{array}{l}\text { Fear avoidance beliefs } \\
\text { (FABQ) }\end{array}$ & & & & $\begin{array}{l}0.044 \\
(0.01 \text { to } 0.07)\end{array}$ & 0.016 & $0.189(0.005)$ \\
\hline$R^{2}$ & 0.149 & & & 0.516 & & \\
\hline $\mathrm{R}^{2}$ change & 0.149 & & & 0.367 & & \\
\hline$F$ for change in $R^{2}$ & $F(3,196)=11.4$ & $(<0.0001)$ & & $F(7,189)=20.507$ & $=0.0001)$ & \\
\hline Adjusted $\mathrm{R}^{2}$ & 0.136 & & & 0.491 & & \\
\hline
\end{tabular}

B, unstandardised beta; $\beta$, standardised beta; BIPQ, Brief Illness Perception Questionnaire; BPS, Back Performance Scale; BS-11,11-point box scale; CSQ, Coping Strategies Questionnaire; FABQ, Fear Avoidance Beliefs Questionnaire; HADS, Hospital Anxiety and Depression Scale; MSPSS, Multidimensional Scale of Perceived Social Support; SEB, SE of beta.

need for self-management, which in turn may influence illness identity, perceived timeline and personal control, respectively. The disparities in the dimensions of illness perceptions may also be due to different illness perception questionnaires and analyses used. For instance, the brief version of the illness perception questionnaire was used in this study, whereas the comprehensive version was used in other studies. ${ }^{43} 45$ Additionally, the causal dimension of illness perceptions was not involved in the

Table 7 Sequential multiple regression analyses of BIPQ items predicting self-reported disability (RMDQ)

\begin{tabular}{|c|c|c|c|c|c|}
\hline \multirow[b]{2}{*}{ Variable, $\mathbf{n = 2 0 0}$} & \multicolumn{2}{|l|}{$\mathrm{B}=$ unstandardised } & \multicolumn{2}{|l|}{$\beta=$ standardised } & \multirow[b]{2}{*}{ Adjusted R } \\
\hline & B (95\% Cl) & SEB & $\beta$ (p value) & $\mathbf{R}^{2}$ & \\
\hline BIPQ total score & 0.215 (0.14 to 0.29$)$ & 0.038 & $0.289(<0.0001)$ & 0.647 & 0.625 \\
\hline Consequences & 0.713 (0.432 to 0.994$)$ & 0.142 & $0.287(<0.0001)$ & 0.635 & 0.612 \\
\hline Timeline & 0.447 (0.162 to 0.732$)$ & 0.144 & $0.157(0.002)$ & 0.606 & 0.581 \\
\hline Personal control & $-0.034(-0.310$ to 0.241$)$ & 0.140 & $-0.012(0.807)$ & 0.586 & 0.560 \\
\hline Treatment control & 0.384 (0.091 to 0.676$)$ & 0.148 & $0.133(0.010)$ & 0.601 & 0.575 \\
\hline Identity & $0.527(0.227$ to 0.827$)$ & 0.152 & $0.202(0.001)$ & 0.611 & 0.586 \\
\hline Illness concern & 0.830 (0.558 to 1.102$)$ & 0.138 & $0.316(<0.0001)$ & 0.653 & 0.631 \\
\hline Coherence & $0.101(-0.181$ to 0.383$)$ & 0.143 & $0.038(0.482)$ & 0.587 & 0.561 \\
\hline Emotional representation & 0.634 (0.396 to 0.872$)$ & 0.121 & $0.299(<0.0005)$ & 0.639 & 0.616 \\
\hline
\end{tabular}

Significant at Bonferroni 0.0063 level (two-tailed).

RMDQ, Roland Morris Disability Questionnaire; BIPQ, Brief Illness Perception Questionnaire; BIPQ1, consequences; BIPQ2, timeline; BIPQ3, personal control; BIPQ4, treatment control; BIPQ5, identity; BIPQ6, illness concern; BIPQ7, coherence; BIPQ8, emotional representation. 
Table 8 Sequential multiple regression analysis of BIPQ items predicting BPS

\begin{tabular}{|c|c|c|c|c|c|}
\hline \multirow[b]{2}{*}{ Variable, $\mathrm{n}=\mathbf{2 0 0}$} & \multicolumn{2}{|l|}{$\mathrm{B}=$ unstandardised } & \multicolumn{2}{|l|}{$\beta=$ standardised } & \multirow[b]{2}{*}{ Adjusted $\mathrm{R}^{2}$} \\
\hline & B (95\% Cl) & SEB & $\beta$ (p value) & $\mathbf{R}^{2}$ & \\
\hline BIPQ total score & 0.154 (0.110 to 0.200$)$ & 0.024 & $0.366(<0.0001)$ & 0.516 & 0.491 \\
\hline Consequences & $0.314(0.125$ to 0.502$)$ & 0.095 & $0.223(0.001)$ & 0.444 & 0.414 \\
\hline Timeline & 0.410 (0.221 to 0.600$)$ & 0.096 & $0.255(<0.0001)$ & 0.464 & 0.435 \\
\hline Personal control & $-0.322(-0.500$ to 0.143$)$ & 0.09 & $-0.205(<0.0001)$ & 0.449 & 0.420 \\
\hline Treatment control & $-0.173(-0.376$ to 0.030$)$ & 0.103 & $-0.106(0.095)$ & 0.420 & 0.390 \\
\hline Identity & 0.222 (0.020 to 0.424$)$ & 0.103 & $0.150(0.032)$ & 0.426 & 0.396 \\
\hline Illness concern & $0.437(0.250$ to 0.623$)$ & 0.095 & $0.294(<0.0001)$ & 0.471 & 0.443 \\
\hline Coherence & $0.024(-0.165$ to 0.214$)$ & 0.096 & $0.016(0.803)$ & 0.412 & 0.381 \\
\hline Emotional representation & $0.220(0.055$ to 0.385$)$ & 0.084 & $0.183(0.009)$ & 0.433 & 0.402 \\
\hline
\end{tabular}

Significant at Bonferroni 0.0063 level (two-tailed).

BPS, Back Performance Scale; BIPQ, Brief Illness Perception Questionnaire; BIPQ1, consequences; BIPQ2, timeline; BIPQ3, personal control; BIPQ4, treatment control; BIPQ5, identity; BIPQ6, illness concern; BIPQ7, coherence; BIPQ8, emotional representation.

regression analyses in this study but was included in the other studies.

In this study, the perceived cause of CLBP is significantly associated with disability, supporting findings in the UK. ${ }^{45}$ Not knowing the cause of CLBP was associated with self-reported and performance-based disability in this study. Attributing spiritual factors to CLBP was significantly associated with self-reported but not performance-based disability. Attributing CLBP to hereditary/ gender factors was significantly associated with performance-based but not self-reported disability. The causal associations must be interpreted with caution however, due to the pronounced unequal sizes of the causal categories of CLBP (table 9).

However, results in the $\mathrm{UK}^{45}$ contradict the results of this study with regard to fear avoidance beliefs. One

Table 9 Influence of perceived causal factors (BIPQ 9) on self-reported (RMDQ) and performance-based (BPS) disability

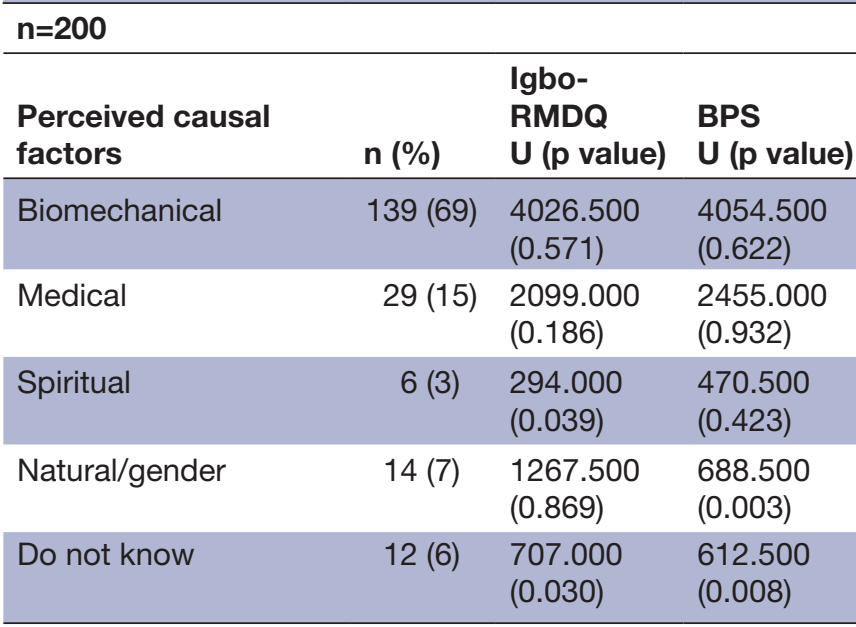

BIPQ, Brief Illness Perception Questionnaire; BPS, Back

Performance Scale; RMDQ, Roland Morris Disability

Questionnaire; U, Mann-Whitney U test. reason could be because of a lack of pain self-efficacy assessment in this study, although both concepts are believed to overlap to some extent. ${ }^{76}$ When all independent factors associated with disability were included in that study, fear avoidance beliefs, depression and catastrophising became non-significant. ${ }^{45}$ In that prospective cohort study, 20 psychological constructs included 12 constructs of illness perceptions, 2 constructs (anxiety and depression) of emotional distress, 1 construct of pain self-efficacy, 1 construct of fear avoidance and 4 constructs of coping strategies. ${ }^{45}$ Pain self-efficacy is the level of confidence a patient has in performing normal tasks in spite of pain, ${ }^{45}$ and has been shown to be a better determinant of pain-related disability than fear avoidance beliefs in primary care patients. ${ }^{45} 76$ Increased pain self-efficacy has also been reported to predict lower performance-based disability, ${ }^{78}$ and has been proposed to act as a mediator of the relationship between pain intensity and CLBP disability. ${ }^{79}$

Another reason for differences in fear avoidance beliefs outcomes could be different population characteristics. Other studies involved patients recruited from primary or occupational healthcare in Western countries, ${ }^{45} 7677$ whereas this study recruited rural Nigerian participants from the community. Bolstering the findings from this study, fear avoidance beliefs have been shown to predict pain-related disability and activities of daily living in population-based samples. ${ }^{40}{ }^{80}$ Fear avoidance beliefs are reportedly higher in tertiary care patients (those receiving specialist care) in high-income countries because they are a highly selected group with worse general baseline outcomes than those in primary care patients. ${ }^{77}$ These patients often have high levels of psychological distress, since most of them have received several failed treatments for CLBP. ${ }^{81}$ The rural Nigerian community dwelling adults in this study, like other population-based samples, ${ }^{40} 80$ are likely to be a mixture of typical primary and tertiary care patients, explaining 
the significance of fear avoidance beliefs. Fear avoidance beliefs may lead to avoidance of movement and activities. ${ }^{82}$ Avoidance of anticipated pain provoking situations is followed by disuse and deconditioning, resulting in muscle strength deficits, ${ }^{83}$ pain and disability. ${ }^{39} 828485$ These mechanisms may therefore explain the prediction of both self-reported and performance-based CLBP disability by fear avoidance beliefs, similarly reported by other authors. ${ }^{868}$

Pain intensity, catastrophising and anxiety were the other factors that predicted self-reported disability, with depression barely reaching statistical significance, whereas social support and female gender predicted performance-based disability. Pain intensity, catastrophising, anxiety and depression have been previously reported to be clearly associated with self-reported disability in high-income countries. ${ }^{30} 3233398284868889$ The fact that pain intensity, catastrophising, anxiety and depression predicted self-reported but not performance-based disability may be due to the fact that performance-based disability assessed actual mobility-related functional capacity, while self-reported disability included life activities that may be more affected by negative emotions.

Pain intensity, ${ }^{8690} 91$ catastrophising, ${ }^{90}$ anxiety $^{78}$ and depression ${ }^{86} 92$ have been shown to have minimal or no association with performance-based disability. Pain intensity was not a significant predictor of performance-based disability probably because pain is a subjective experience, more in line with self-reported disability than with the more objective performance-based disability. The nearly insignificant association of depression and weak association of anxiety with self-reported disability in this study could be related to poor or divergent understanding and expression of these emotional concepts in this population, as suggested in a qualitative study. ${ }^{50}$ Moreover, distress may be better reflected in some of the illness perception dimensions, such as illness concern and emotional representations, which were found to be strong predictors of CLBP disability in this study.

Catastrophising has been reported as a predictor ${ }^{87}$ and precursor $^{82} 84$ of fear avoidance beliefs, which may explain its stronger association with self-reported disability than fear avoidance beliefs, and lack of association with performance-based disability. Disuse and deconditioning, underlying performance-based disability, ${ }^{93}$ may be more directly linked to fear avoidance beliefs than catastrophising, pain intensity, anxiety and depression. However, the evidence linking disuse and deconditioning to CLBP disability is ambiguous. Disuse and deconditioning have been explained in terms of reduced muscle strength, muscle coordination and aerobic fitness. ${ }^{39} 8284$ As opposed to muscle strength and muscle coordination which may be masked by submaximal performance due to fear avoidance beliefs, aerobic fitness capacity is regarded as a better assessment of disuse and deconditioning. ${ }^{84}$ However, reduced muscle strength and muscle coordination but not aerobic fitness, have been clearly associated with CLBP disability. ${ }^{84}{ }_{93}$
This suggests that only some specific activities believed to aggravate pain may be reduced, while general physical activity levels and cardiovascular fitness remain unaffected in CLBP. ${ }^{84} 93$ This corroborates the findings in this population suggesting that people with CLBP are physically active despite apparent disability. ${ }^{50}$

Social support was negatively associated with self-reported disability measured with the WHODAS. Evidence suggests that qualitative aspects of perceived social support and quantitative aspects of the size of social networks affect long-term functional limitations and pain in chronic pain conditions. ${ }^{94} 95$ Increased social support has been associated with less limitation in daily life, fewer pain behaviours, greater activity levels, adaptive coping and better adjustment to chronic pain. ${ }^{94}{ }^{95}$ Conversely, the positive association of social support with performance-based disability in this study may be because increased social support was a consequence of mobility limitation, as social support often signifies coping assistance. ${ }^{96}$ It may also be that too much social support is detrimental to mobility. The social aspect of the biopsychosocial model of CLBP has received the least attention in other studies, which has adverse implications for low-income and socially deprived patients. ${ }^{97}$

Occupational biomechanical factors were negatively associated with self-reported disability, although this became non-significant with Bonferroni correction, and had no significant association with performance-based disability. This contradicts the qualitative reports in rural Nigeria suggesting that biomechanical factors such as heavy lifting and prolonged bending were associated with adverse CLBP outcomes. ${ }^{49} 50$ As almost all participants were involved in manually driven jobs, it is possible that higher exposure to occupational biomechanical factors may have highlighted participants still at work despite their CLBP, whereas low exposure to biomechanical factors may represent participants who were no longer at work or had changed their jobs due to CLBP. This supports previous qualitative reports suggesting that some individuals left or changed their jobs due to CLBP in rural Nigeria. ${ }^{50}$ However, biomechanical factors have been linked to fear avoidance beliefs. ${ }^{82} 98$ High physical work load combined with fear avoidance beliefs may be associated with hypervigilance, and anticipation of pain during work-related activities, ${ }^{82} 9899$ which may in turn lead to muscle guarding and co-contraction, increasing pain and CLBP disability. ${ }^{82} 100$ Alternatively, participants may have perceived biomechanical factors to be more important than they actually were. In high-income countries, greater exposure to biomechanical factors such as lifting, bending, twisting, digging or shovelling, has been associated with poor return to work outcomes. ${ }^{48}$ However, the disability measures used in the multiple regression analyses in this study did not capture work-related outcomes.

Our study has some limitations. The sample in this study may not be representative of the wider rural populations in Nigeria. The cross-sectional design of this study 
constrains the establishment of temporal relationships between the investigated biopsychosocial factors and CLBP disability. It is possible that the involvement of 10 different CHWs to collect data may have added some bias that was not detected, even though stringent efforts were made to counteract this via training and supervision. Nevertheless, the use of CHWs enabled the collection of a large data set that facilitated the robust results presented in this paper.

Our results suggest that psychosocial factors may be more important than biomechanical factors in explaining CLBP disability in rural Nigeria. This is at odds with current management in this context, which is based on a biomedical model. ${ }^{49101}$ There needs to be a paradigm shift in the management of CLBP in rural Nigeria to acknowledge psychosocial factors. This could be achieved through training curriculum based on a biopsychosocial model. Health professionals will need to be trained in biopsychosocial approaches of assessment and interpretation of patients' conditions. For instance, how clinical interviewing or subjective assessment could be modified to identify psychosocial factors, how subjective findings can be interpreted and how psychosocial factors can be targeted clinically. Cognitive behavioural and motivational strategies combined with exercise therapy may prove beneficial but require considerable training. Advocacy campaigns involving health and education policy makers and stakeholders may be needed to enable modification of training across Nigerian universities and clinical practice across Nigerian healthcare facilities. However, as suggested in high-income countries, this is not a simple matter, and there may be resistance to adopting new clinical approaches or lack of resources to implement them. Considerable time and effort may therefore be required to modify health professionals' beliefs, and translate training into practice.

\section{Author affiliations \\ 'Department of Medical Rehabilitation, Faculty of Health Sciences and Technology, College of Medicine, University of Nigeria (Enugu Campus), Nsukka, Nigeria ${ }^{2}$ NIHR Biomedical Research Centre at Guy's and St Thomas', NHS Foundation Trust and King's College London, United Kingdom \\ ${ }^{3}$ Department of Community Medicine, Faculty of Medical Sciences, College of Medicine, University of Nigeria, Nigeria \\ ${ }^{4}$ Department of Physiotherapy, School of Population Health Sciences, Faculty of Life Sciences and Medicine, King's College London, United Kingdom}

Contributors CNI-C, ELG and IOS conceived and designed the study. CNI-C and CNO collected the data. CNI-C inputed the data into software. CNI-C analysed and interpreted the data, cross-checked by BC and ELG. CNI-C drafted the initial manuscript. All authors contributed to a revised edition of the manuscript. CNI-C prepared the final manuscript.

Funding University of Nigeria/Schlumberger faculty for the future, The Netherlands.

Competing interests None declared.

Ethics approval Research Ethics Committees of King's College London (Ref: BDM/13/14-99) and University of Nigeria Teaching Hospital (Ref: UNTH/CSA/329/ Vol.5).

Provenance and peer review Not commissioned; externally peer reviewed.

Data sharing statement № additional data are available.
Open Access This is an Open Access article distributed in accordance with the Creative Commons Attribution Non Commercial (CC BY-NC 4.0) license, which permits others to distribute, remix, adapt, build upon this work non-commercially, and license their derivative works on different terms, provided the original work is properly cited and the use is non-commercial. See: http://creativecommons.org/ licenses/by-nc/4.0/

(c) Article author(s) (or their employer(s) unless otherwise stated in the text of the article) 2017. All rights reserved. No commercial use is permitted unless otherwise expressly granted.

\section{REFERENCES}

1. Vos T, Barber RM, Bell B, et al. Global, regional, and national incidence, prevalence, and years lived with disability for 301 acute and chronic diseases and injuries in 188 countries, 1990-2013: a systematic analysis for the Global Burden of Disease Study 2013. Lancet 2015;386:743-800.

2. Hoy D, Bain C, Williams G, et al. A systematic review of the global prevalence of low back pain. Arthritis Rheum 2012;64:2028-37.

3. Hoy D, March L, Brooks P, et al. Measuring the global burden of low back pain. Best Pract Res Clin Rheumatol 2010;24:155-65.

4. Hoy DG, Smith E, Cross M, et al. Reflecting on the global burden of musculoskeletal conditions: lessons learnt from the global burden of disease 2010 study and the next steps forward. Ann Rheum Dis 2015;74:4-7.

5. Hoy D, Brooks P, Blyth F, et al. The epidemiology of low back pain. Best Pract Res Clin Rheumatol 2010;24:769-81.

6. Hoy D, Toole MJ, Morgan D, et al. Low back pain in rural Tibet. The Lancet 2003;361:225-6.

7. Hondras M, Hartvigsen J, Myburgh C, et al. Everyday burden of musculoskeletal conditions among villagers in rural Botswana: $\mathrm{A}$ focused ethnography. J Rehabil Med 2016;48:449-55.

8. Louw QA, Morris LD, Grimmer-Somers K. The prevalence of low back pain in Africa: a systematic review. BMC Musculoskelet Disord 2007;8:105.

9. Omokhodion FO. Low back pain in an urban population in Southwest Nigeria. Trop Doct 2004;34:17-20.

10. Fabunmi AA, Aba SO, Odunaiya NA. Prevalence of low back pain among peasant farmers in a rural community in South West Nigeria. Afr J Med Med Sci 2005;34:259-62.

11. Andersson GB. Epidemiological features of chronic low-back pain. Lancet 1999;354:581-5.

12. Tella BA, Akinbo SR, Asafa SA, et al. Prevalence and impacts of low back pain among peasant farmers in south-west Nigeria. Int $J$ Occup Med Environ Health 2013;26:621-7.

13. Birabi BN, Dienye PO, Ndukwu GU. Prevalence of low back pain among peasant farmers in a rural community in South South Nigeria. Rural Remote Health 2012:12.

14. Broonen JP, Marty M, Legout V, et al. Is volition the missing link in the management of low back pain? Joint Bone Spine 2011;78:364-7.

15. Rozenberg S, Foltz V, Fautrel B. Treatment strategy for chronic low back pain. Joint Bone Spine 2012;79:555-9.

16. Itz CJ, Geurts JW, van Kleef M, et al. Clinical course of non-specific low back pain: a systematic review of prospective cohort studies set in primary care. Eur J Pain 2013;17:5-15.

17. Woolf $A D$, Pfleger B. Burden of major musculoskeletal conditions. Bull World Health Organ 2003;81:646-56.

18. Igwesi-Chidobe CN, Okafor Udoka AC. Community physiotherapy and rehabilitation outcomes in Nigeria: knowledge, attitude and practice of physiotherapists in Enugu state. IJHSR 2013;3:37-44.

19. Ebuehi OM, Campbell PC, Campbell OEP. Attraction and retention of qualified health workers to rural areas in Nigeria: a case study of four LGAs in Ogun State, Nigeria. Rural Remote Health 2011;11 http://www.rrh.org.au

20. Ojua T, Ishor D, Ndom P. African cultural practices and health for Nigeria rural development. IRMBR 2013;2:176-83.

21. Igwesi-Chidobe C. Obstacles to obtaining optimal physiotherapy services in a rural community in Southeastern Nigeria. Rehabil Res Pract 2012;2012:1-8.

22. Abdulraheem IS. Health needs assessment and determinants of health-seeking behaviour among elderly Nigerians: A house-hold survey. Ann Afr Med 2007;6:58-63.

23. Hondras M, Myburgh C, Hartvigsen J, et al. How can we assess the burden of muscle, bone and joint conditions in rural Botswana: context and methods for the MuBoJo focused ethnography. Chiropr Man Therap 2015;23:11. 
24. Sanya AO, Omokhodion F, Ogwumike O. Risk factors for low back pain among hospital workers in Ibadan, Oyo State, Nigeria. JNSP 2009;15:31-4.

25. Sanya AO, Ogwumike OO. Low back pain prevalence amongst industrial workers in the private sector in Oyo State, Nigeria. Afr $J$ Med Med Sci 2005;34:245-9.

26. Omokhodion FO, Sanya AO. Risk factors for low back pain among office workers in Ibadan, Southwest Nigeria. Occup Med 2003:53:287-9.

27. Adeyemi SA, Akanbi O, Ismaila S. Manual lifting task methods and low back pain among construction workers in the Southwestern Nigeria. GJRE 2013;13:2249-4596.

28. Linton SJ. A review of psychological risk factors in back and neck pain. Spine 2000;25:1148-56.

29. Gatchel RJ, Peng YB, Peters ML, et al. The biopsychosocial approach to chronic pain: scientific advances and future directions. Psychol Bull 2007;133:581-624.

30. Turk DC, Okifuji A. Psychological factors in chronic pain: evolution and revolution. J Consult Clin Psychol 2002;70:678-90.

31. Kamper SJ, Apeldoorn AT, Chiarotto A, et al. Multidisciplinary biopsychosocial rehabilitation for chronic low back pain: Cochrane systematic review and meta-analysis. $B M J$ 2015;350:h444.

32. Nicholas MK, Linton SJ, Watson PJ, et al. Early identification and management of psychological risk factors ("yellow flags") in patients with low back pain: a reappraisal. Phys Ther 2011;91:737-53.

33. Pincus T, Burton AK, Vogel S, et al. A systematic review of psychological factors as predictors of chronicity/disability in prospective cohorts of low back pain. Spine 2002;27:E109-E120.

34. Ramond A, Bouton C, Richard I, et al. Psychosocial risk factors for chronic low back pain in primary care - a systematic review. Family Practice 2011;8:12-21.

35. Bair MJ, Wu J, Damush TM, et al. Association of depression and anxiety alone and in combination with chronic musculoskeletal pain in primary care patients. Psychosom Med 2008;70:890-7.

36. Iles RA, Davidson M, Taylor NF. Psychosocial predictors of failure to return to work in non-chronic non-specific low back pain: a systematic review. Occup Environ Med 2008;65:507-17.

37. Wertli MM, Rasmussen-Barr E, Held U, et al. Fear-avoidance beliefs - a moderator of treatment efficacy in patients with low back pain: a systematic review. The Spine Journal 2014;14:2658-78.

38. Rainville J, Smeets RJEM, Bendix T, et al. Fear-avoidance beliefs and pain avoidance in low back pain - translating research into clinical practice. The Spine Journal 2011;11:895-903.

39. Vlaeyen JWS, Linton SJ. Fear-avoidance model of chronic musculoskeletal pain: 12 years on. Pain 2012;153:1144-7.

40. Picavet HSJ, Vlaeyen JW, Schouten JS. Pain catastrophizing and kinesiophobia: predictors of chronic low back pain. Am J Epidemiol 2002;156:1028-34.

41. Lynch AM, Kashikar-Zuck S, Goldschneider KR, et al. Psychosocial risks for disability in children with chronic back pain. J Pain 2006; 7:244-51.

42. Wertli MM, Eugster R, Held U, et al. Catastrophizing-a prognostic factor for outcome in patients with low back pain: a systematic review. Spine J 2014;14:2639-57.

43. Foster NE, Bishop A, Thomas E, et al. Illness perceptions of low back pain patients in primary care: what are they, do they change and are they associated with outcome? Pain 2008;136:177-87.

44. Galli U, Ettlin DA, Palla S, et al. Do illness perceptions predict painrelated disability and mood in chronic orofacial pain patients? A 6-month follow-up study. Eur J Pain 2010;14:550-8.

45. Foster NE, Thomas E, Bishop A, et al. Distinctiveness of psychological obstacles to recovery in low back pain patients in primary care. Pain 2010;148:398-406.

46. Steenstra IA, Verbeek J, Heymans M, Bongers P. Prognostic factors for duration of sick leave in patients sick listed with acute low back pain: a systematic review of the literature. Occup Environ Med 2005;62:851-60.

47. Fransen $M$, Woodward $M$, Norton $R$, et al. Risk factors associated with the transition from acute to chronic occupational back pain. Spine 2002;27:92-8.

48. McNee P, Shambrook J, Harris EC, et al. Predictors of long-term pain and disability in patients with low back pain investigated by magnetic resonance imaging: A longitudinal study. BMC Musculoskelet Disord 2011;12.

49. Igwesi-Chidobe CN, Kitchen S, Sorinola IO, et al. Qualitative exploration of non-specific chronic low back pain in rural Nigeria: towards evidence-informed physiotherapy practice. Physiotherapy 2015;101:e636-e637.
50. Igwesi-Chidobe CN, Kitchen S, Sorinola IO, et al. "A life of living death": the experiences of people living with chronic low back pain in rural Nigeria. Disabil Rehabil 2017;39:779-90.

51. von Elm E, Altman DG, Egger M, et al. The strengthening the reporting of observational studies in epidemiology (STROBE) statement: guidelines for reporting observational studies. Prev Med 2007:45:247-51.

52. Nigeria Government. Census figures (population) [Online]. Nigeria, 2006. http://www.nigeriamasterweb.com/Nigeria06CensusFigs. htm

53. Enugu State Government. Enugu State Government, state official website [Online]. http://www.enugustate.gov.ng/

54. Downie A, Williams CM, Henschke N, et al. Red flags to screen for malignancy and fracture in patients with low back pain: systematic review. BMJ 2013;347:f7095.

55. Chou R, Qaseem A, Snow V, et al. iagnosis and treatment of low back pain: a joint clinical practice guideline from the American College of Physicians and the American Pain Society. Ann Intern Med 2007;147:478-91.

56. Airaksinen O, Brox Jl, Cedraschi C, et al. Chapter 4 European guidelines for the management of chronic nonspecific low back pain. European Spine Journal 2006;15(S2):s192-s300.

57. Koes BW, van Tulder M, Lin CW, et al. An updated overview of clinical guidelines for the management of non-specific low back pain in primary care. Eur Spine J 2010;19:2075-94.

58. NICE. Low back pain: early management of persistent nonspecific low back pain. 88: The National Institute for Health and Clinical Excellence (NICE), 2009. https://www.nice.org.uk/ guidance/cg88

59. Beaton DE, Bombardier C, Guillemin F, et al. Guidelines for the process of cross-cultural adaptation of self-report measures. Spine 2000;25:3186-91.

60. Strand LI, Moe-Nilssen R, Ljunggren AE. Back performance scale for the assessment of mobility-related activities in people with back pain. Phys Ther 2002;82:1213-23.

61. Roland M, Morris R. A study of the natural history of back pain. Part I: development of a reliable and sensitive measure of disability in low-back pain. Spine 1983;8:141-4.

62. Üstün TB. Measuring health and disability: manual for WHO disability assessment schedule WHODAS 2.0: World Health Organization, 2010.

63. Üstün TB, Chatterji S, Kostanjsek N, et al. Developing the World Health Organization disability assessment schedule 2.0. Bull World Health Organ 2010;88:815-23.

64. Downie WW, Leatham PA, Rhind VM, et al. Studies with pain rating scales. Ann Rheum Dis 1978;37:378-81.

65. Hawker GA, Mian S, Kendzerska T, et al. Measures of adult pain: Visual analog scale for pain (VAS Pain), numeric rating scale for pain (NRS Pain), McGill pain questionnaire (MPQ), short-form McGill pain questionnaire (SF-MPQ), chronic pain grade Scale (cpgs), short form-36 bodily pain scale (sf-36 BPS), and measure of intermittent and constant osteoarthritis pain (ICOAP). Arthritis Care Res 2011;63(S11):S240-S252.

66. Jensen MP, Karoly P, Braver S. The measurement of clinical pain intensity: a comparison of six methods. Pain 1986;27:117-26.

67. Dworkin RH, Turk DC, Farrar JT, et al. Core outcome measures for chronic pain clinical trials: IMMPACT recommendations. Pain 2005;113(1):9-19.

68. Dannecker EA, George SZ, Robinson ME. Influence and stability of pain scale anchors for an investigation of cold pressor pain tolerance. J Pain 2007;8:476-82.

69. Zigmond AS, Snaith RP. The hospital anxiety and depression scale. Acta Psychiatr Scand 1983;67:361-70.

70. Rosenstiel AK, Keefe FJ. The use of coping strategies in chronic low back pain patients: relationship to patient characteristics and current adjustment. Pain 1983;17:33-44.

71. Zimet GD, Dahlem NW, Zimet SG, et al. The multidimensional scale of perceived social support. J Pers Assess 1988;52:30-41.

72. Broadbent E, Petrie KJ, Main J, et al. The brief illness perception questionnaire. J Psychosom Res 2006;60:631-7.

73. Waddell G, Newton M, Henderson I, et al. A fear-avoidance beliefs questionnaire $(\mathrm{FABQ})$ and the role of fear-avoidance beliefs in chronic low back pain and disability. Pain 1993;52:157-68.

74. Halpern M, Hiebert R, Nordin M, et al. The test-retest reliability of a new occupational risk factor questionnaire for outcome studies of low back pain. Appl Ergon 2001;32:39-46.

75. Broadbent $\mathrm{E}$, Wilkes $\mathrm{C}$, Koschwanez $\mathrm{H}$, et al. A systematic review and meta-analysis of the Brief Illness Perception Questionnaire. Psychol Health 2015;30:1361-85.

76. Ayre M, Tyson GA. The role of self-efficacy and fear-avoidance beliefs in the prediction of disability. Aust Psychol 2001;36:250-3. 
77. Denison E, $\square$ senlöf P, Lindberg P. Self-efficacy, fear avoidance, and pain intensity as predictors of disability in subacute and chronic musculoskeletal pain patients in primary health care. Pain 2004;111:245-52.

78. Lackner JM, Carosella AM. The relative influence of perceived pain control, anxiety, and functional self efficacy on spinal function among patients with chronic low back pain. Spine 1999;24:2254.

79. Truchon M. Determinants of chronic disability related to low back pain: towards an integrative biopsychosocial model. Disabil Rehabil 2001;23:758-67.

80. Buer N, Linton SJ. Fear-avoidance beliefs and catastrophizing: occurrence and risk factor in back pain and ADL in the general population. Pain 2002;99:485-91.

81. Walker J, Sofaer B, Holloway I. The experience of chronic back pain: accounts of loss in those seeking help from pain clinics. Eur $J$ Pain 2006;10:199.

82. Vlaeyen JWS, Linton SJ. Fear-avoidance and its consequences in chronic musculoskeletal pain: a state of the art. Pain 2000;85:317-32

83. Al-Obaidi SM, Nelson RM, Al-Awadhi S, et al. The role of anticipation and fear of pain in the persistence of avoidance behavior in patients with chronic low back pain. Spine 2000;25:1126-31.

84. Leeuw M, Goossens MEJB, Linton SJ, et al. The fear-avoidance model of musculoskeletal pain: current state of scientific evidence. J Behav Med 2007;30:77-94.

85. Swinkels-Meewisse IEJ, Roelofs J, Oostendorp RAB, et al. Acute low back pain: pain-related fear and pain catastrophizing influence physical performance and perceived disability. Pain 2006;120:36-43.

86. Schiphorst Preuper HR, Reneman MF, Boonstra AM, et al. Relationship between psychological factors and performancebased and self-reported disability in chronic low back pain. Eur Spine J 2008;17:1448-56.

87. Vlaeyen JWS, Kole-Snijders AMJ, Boeren RGB, et al. Fear of movement/(re)injury in chronic low back pain and its relation to behavioral performance. Pain 1995;62:363-72.

88. Koleck M, Mazaux JM, Rascle N, et al. Psycho-social factors and coping strategies as predictors of chronic evolution and quality of life in patients with low back pain: a prospective study. Eur J Pain 2006;10:1-11.
89. Radat F, Koleck M. Pain and depression: cognitive and behavioural mediators of a frequent association]. L'Encéphale 2011;37:172-9.

90. Smeets RJ, van Geel AC, Kester AD, et al. Physical capacity tasks in chronic low back pain: what is the contributing role of cardiovascular capacity, pain and psychological factors? Disabil Rehabil 2007;29:577-86.

91. Odebiyi DO, Kujero S, Lawal T. Relationship between spinal mobility, physical performance, pain intensity and functional disability in patients with chronic low back pain. Niger J Med Rehabil 2007;11:49-54.

92. Geisser ME. Activity avoidance and function in persons with chronic back pain. J Occup Rehabil 2000;10:215-27.

93. Brox JI, Storheim K, Holm I, et al. Disability, pain, psychological factors and physical performance in healthy controls, patients with sub-acute and chronic low back pain: a case-control study. $J$ Rehabil Med 2005;37:95-9.

94. Evers AWM, Kraaimaat FW, Geenen R, et al. Pain coping and socia support as predictors of long-term functional disability and pain in early rheumatoid arthritis. Behav Res Ther 2003;41:1295-310.

95. Klapow JC, Slater MA, Patterson TL, et al. Psychosocial factors discriminate multidimensional clinical groups of chronic low back pain patients. Pain 1995;62:349-55.

96. Thoits PA. Social support as coping assistance. J Consult Clin Psychol 1986;54:416-23.

97. Carr JL, Klaber Moffett JA, Moffett JA. The impact of social deprivation on chronic back pain outcomes. Chronic IIIn 2005;1:121-9.

98. Al-Obaidi SM, Beattie P, Al-Zoabi B, et al. The relationship of anticipated pain and fear avoidance beliefs to outcome in patients with chronic low back pain who are not receiving workers' compensation. Spine 2005;30:1051-7.

99. Van Nieuwenhuyse A, et al. The role of physical workload and pain related fear in the development of low back pain in young workers: evidence from the BelCoBack Study; results after one year of follow up. Occup Environ Med 2006;63:45-52.

100. Vibe Fersum K, O'Sullivan P, Skouen JS, et al. Efficacy of classification-based cognitive functional therapy in patients with non-specific chronic low back pain: a randomized controlled trial. Eur J Pain 2013;17:916-28.

101. Ayanniyi O, Lasisi O, Adegoke B, et al. Management of low back pain: attitudes and treatment preferences of physiotherapists in Nigeria. Afr J Biomed Res 2007;2007:41-9. 